\title{
Effects of mediastinal irradiation on oesophageal function
}

\author{
E Yeoh, R H Holloway, A Russo, M Tippett, H Bermingham, B Chatterton, M Horowitz
}

\begin{abstract}
Although it is well recognised that oesophageal symptoms are common during therapeutic mediastinal irradiation of intrathoracic malignant diseases, the effects of mediastinal irradiation on oesophageal function are poorly defined. To clarify the pathogenesis of these sequelae a prospective study was performed to document comprehensively the effects of mediastinal irradiation on oesophageal function. Oesophageal symptoms, barium swallow, endoscopy, and combined radionuclide scintigraphy and oesophageal manometry were evaluated in eight patients with potentially curable intrathoracic malignant disease before treatment, during the last week of mediastinal irradiation, and six to eight weeks after its completion. Before irradiation, structural abnormalities were excluded by barium swallow and endoscopy. All but one patient experienced odynophagia or dysphagia, or both, during mediastinal irradiation $(\mathbf{p}<0.001)$ but endoscopic abnormalities were observed in only three patients and there was no correlation between oesophageal symptoms and endoscopic changes. Irradiation, however, had no significant effect on oesophageal motility or transit. It is concluded that oesophageal symptoms which develop during mediastinal irradiation are not a result of altered oesophageal motility or transit and may reflect increased mucosal sensitivity. (Gut 1996; 38: 166-170)
\end{abstract}

Keywords: oesophageal function, oesophageal motility, mediastinal irradiation, malignancy.

Dysphagia and substernal burning are almost inevitable during the course of therapeutic mediastinal irradiation for intrathoracic malignant diseases and may be severe enough to interrupt treatment. ${ }^{1}$ The resulting prolongation in the course of treatment may compromise the chance of cure. ${ }^{12}$ The pathogenesis of these sequelae, however, is poorly understood; in particular, it is uncertain whether symptoms arise as a result of oesophageal mucosal damage or disordered oesophageal motility. Mucosal damage has been documented in two prospective studies ${ }^{34}$ but its severity does not correlate with symptoms. Delayed oesophageal transit reported in patients undergoing mediastinal irradiation also correlates poorly with oesophageal symptoms. ${ }^{5}$ There have been no manometric studies, however, to correlate possible changes in oesophageal transit with motility. This study aimed, therefore, to investigate prospectively the relationships among oesophageal symptoms, mucosal damage, and motility changes in patients undergoing therapeutic mediastinal irradiation for non-oesophageal malignancy.

\section{Methods}

We studied eight patients, (five women, three men) with a median age of 68 years (range 53-85 years), a median body weight of $75.9 \mathrm{~kg}$ $(62-120.9 \mathrm{~kg})$ and a median body mass index (BMI) $26 \cdot 2(21 \cdot 7-42 \cdot 8)$. They were undergoing mediastinal irradiation for potentially curable carcinoma of the lung (four patients), Hodgkin's lymphoma (one patient), and breast carcinoma (three patients). Characteristics of the patients and radiation dosimetry are summarised in Table I. Patients with a history of oesophageal surgery or disordered oesophageal motility, and those with evidence of oesophageal involvement by the malignant process as demonstrated by endoscopy or barium swallow, or both, were excluded. No patient received concurrent chemotherapy. The study was approved by the Research Ethics Committee of the Royal Adelaide Hospital and informed consent was obtained from each patient.

Each patient was assessed by symptom questionnaire, barium swallow, endoscopy, and combined radionuclide scintigraphy and oesophageal manometry before irradiation, during the last week of irradiation (four to six weeks after beginning of treatment), and six to eight weeks after stopping irradiation. The various assessments were performed within one week of each other.

\section{SYMPTOM QUESTIONNAIRE}

The following symptoms were assessed at the start of each series of measurements: dysphagia, odynophagia, heartburn, and regurgitation. Heartburn and regurgitation were also included in the questionnaire as pre-existing reflux oesophagitis was not an exclusion criteria and 
TABLE I Characteristics of the patients studied

\begin{tabular}{|c|c|c|c|c|c|c|c|}
\hline $\begin{array}{l}\text { Patient } \\
\text { no }\end{array}$ & $\begin{array}{l}\text { Age } \\
(y)\end{array}$ & $\begin{array}{l}\text { Body } \\
\text { weight } \\
\text { (kg) }\end{array}$ & $\begin{array}{l}\text { Body } \\
\text { mass } \\
\text { index }\end{array}$ & Diagnosis & $\begin{array}{l}\text { Radiation dose } \\
\text { (Gy/no of } \\
\text { fractions/d) }\end{array}$ & $\begin{array}{l}\text { Radiation } \\
\text { field size } \\
(\mathrm{cm} \times \mathrm{cm})\end{array}$ & $\begin{array}{l}\text { Symptom } \\
\text { score during } \\
\text { (before) } \\
\text { radiation }\end{array}$ \\
\hline 1 & 82 & $70 \cdot 0$ & $22 \cdot 8$ & $\begin{array}{l}\text { Carcinoma } \\
\text { (L) lung }\end{array}$ & $\begin{array}{l}30 \mathrm{~Gy} / 15 \mathrm{~F} / 20 \mathrm{~d} \\
20 \mathrm{~Gy} / 10 \mathrm{~F} / 13 \mathrm{~d} \\
10 \mathrm{~Gy} / 5 \mathrm{~F} / 6 \mathrm{~d}\end{array}$ & $\begin{array}{l}15.5 \times 16.0 \\
12.5 \times 10.0 \\
10.0 \times 9.0\end{array}$ & $4(1)$ \\
\hline 2 & 85 & $63 \cdot 5$ & $22 \cdot 2$ & $\begin{array}{r}\text { Carcinoma } \\
\text { (R) lung }\end{array}$ & $\begin{array}{l}30 \mathrm{~Gy} / 15 \mathrm{~F} / 28 \mathrm{~d} \\
30 \mathrm{~Gy} / 15 \mathrm{~F} / 28 \mathrm{~d}\end{array}$ & $\begin{array}{l}15.0 \times 16.5 \\
12.0 \times 11.0\end{array}$ & $3(0)$ \\
\hline 3 & 58 & $120 \cdot 9$ & $42 \cdot 8$ & $\begin{array}{l}\text { Carcinoma } \\
\text { (L) breast }\end{array}$ & $50 \mathrm{~Gy} / 25 \mathrm{~F} / 34 \mathrm{~d}$ & $22 \cdot 0 \times 3 \cdot 4$ & $2(0)$ \\
\hline 4 & 69 & $92 \cdot 2$ & $31 \cdot 7$ & $\begin{array}{l}\text { Hodgkin's } \\
\text { lymphoma }\end{array}$ & $\begin{array}{c}35 \mathrm{~Gy} / 20 \mathrm{~F} / 29 \mathrm{~d} \\
9 \cdot 1 \mathrm{~Gy} / 6 \mathrm{~F} / 7 \mathrm{~d} \\
7.5 \mathrm{~Gy} / 5 \mathrm{~F} / 10 \mathrm{~d}\end{array}$ & $\begin{array}{l}25.0 \times 29.0 \\
14.0 \times 15.5 \\
12.0 \times 9.0\end{array}$ & $4(0)$ \\
\hline 5 & 67 & $71 \cdot 8$ & $29 \cdot 1$ & $\begin{array}{l}\text { Carcinoma } \\
(\mathrm{R}) \text { breast }\end{array}$ & $50 \mathrm{~Gy} / 25 \mathrm{~F} / 32 \mathrm{~d}$ & $22.0 \times 32.0$ & $0(0)$ \\
\hline 6 & 53 & $80 \cdot 0$ & $23 \cdot 4$ & $\begin{array}{l}\text { Carcinoma } \\
\text { (L) lung }\end{array}$ & $\begin{array}{l}30 \mathrm{~Gy} / 15 \mathrm{~F} / 23 \mathrm{~d} \\
10 \mathrm{~Gy} / 15 \mathrm{~F} / 7 \mathrm{~d} \\
20 \mathrm{~Gy} / 10 \mathrm{~F} / 13 \mathrm{~d}\end{array}$ & $\begin{array}{l}15.5 \times 16.0 \\
10.5 \times 11.0 \\
10.5 \times 8.0\end{array}$ & $3(0)$ \\
\hline 7 & 65 & $85 \cdot 5$ & $33 \cdot 4$ & $\begin{array}{l}\text { Carcinoma } \\
\text { (L) breast }\end{array}$ & $50 \mathrm{~Gy} / 25 \mathrm{~F} / 34 \mathrm{~d}$ & $12.5 \times 28.0$ & $5(3)$ \\
\hline 8 & 75 & $62 \cdot 0$ & $21 \cdot 7$ & $\begin{array}{l}\text { Carcinoma } \\
\text { (R) lung }\end{array}$ & $\begin{array}{l}44 \mathrm{~Gy} / 22 \mathrm{~F} / 31 \mathrm{~d} \\
16 \mathrm{~Gy} / 8 \mathrm{~F} / 11 \mathrm{~d}\end{array}$ & $\begin{array}{l}14.5 \times 13.0 \\
10.0 \times 11.0\end{array}$ & $3(0)$ \\
\hline
\end{tabular}

$(\mathrm{R})=$ right; $(\mathrm{L})=$ left. pneumohydraulic capillary infusion pump. ${ }^{7}$ The pharyngeal side hole was perfused at $0 \cdot 13$ $\mathrm{ml} / \mathrm{min}$. Each lumen was connected to an external pressure transducer (Transpac, Abbott Laboratories/Hospital Products Division, North Chicago, Illinois 60064), whose output was recorded on a multichannel chart recorder at a paper speed of $5 \mathrm{~mm} / \mathrm{s}$.

The assembly was passed via an anaesthetised nostril and positioned so that the sleeve straddled the LOS. The patients were then positioned supine and allowed to adapt over a period of 15 minutes. Each patient then undertook a series of 10 dry and 10 water swallows ( $5 \mathrm{ml}$ unlabelled bolus) with an interval of at least 20 seconds between successive swallows.

After the unlabelled swallows, the patients sat up with their backs to a gammacamera. The manometric assembly was repositioned if necessary so that the side hole of the proximal margin of the sleeve was sited $2 \mathrm{~cm}$ above the proximal margin of the LOS. The position of the cricoid cartilage was marked by a labelled cobalt marker and a 5 minute recording of the catheter and cobalt marker was made in order to establish the positions of the markers for subsequent analysis. Each patient then swallowed, in triplicate, $10 \mathrm{gm}$ boluses of cooked hamburger meat labelled with $6 \mathrm{MBq}$ ${ }^{99 m}$ Technetium (Tc). The patient was asked to chew the bolus, swallow it with one swallow, and then to perform dry swallows at 30 second intervals until the bolus was seen to enter the stomach or a total of 5 minutes had elapsed. Images of the entire oesophagus from the pharynx to the gastric fundus were acquired in 1 second frames for the first 150 seconds and 3 second frames for the remaining time.

After assessment of solid transit, the patients lay supine. Transit of liquids was assessed using $5 \mathrm{ml}$ water boluses labelled with $9 \mathrm{MBq}$ ${ }^{99 m}$ Tc. Labelled swallows were taken in triplicate. Each bolus was swallowed in a single swallow and subsequent dry swallows taken at 30 second intervals until the bolus had cleared the oesophagus or 2 minutes had elapsed. Scintigraphic images were acquired in 0.5 second frames starting 10 seconds before the labelled bolus had been swallowed.

\section{DATA ANALYSIS}

\section{SCINTIGRAPHY}

Oesophageal manometry was performed using a multilumen manometric assembly. A sleeve sensor ${ }^{6}$ recorded lower oesophageal sphincter (LOS) pressure. A side hole $1 \mathrm{~cm}$ beyond the distal end of the sleeve recorded intragastric pressure. Additional side holes at the proximal margin of the sleeve and at 4,8 , and $12 \mathrm{~cm}$ proximally recorded pressure in the oesophageal body, and a side hole in the hypopharynx monitored swallowing. The position of each side hole as well as the midpoint of the sleeve was marked by a radioactive cobalt marker for identification during analysis of the scintigraphic studies. The sleeve, gastric, and oesophageal lumens were perfused with degassed distilled water at $0.5 \mathrm{ml} / \mathrm{min}$ by a

\section{Oesophageal manometry}

The manometric tracings of the unlabelled liquid and labelled solid and liquid swallows were analysed for oesophageal contraction amplitude, peristaltic success, and the level of peristaltic failure for the index swallow. Peristaltic failure was defined by a contraction wave of less than $10 \mathrm{~mm} \mathrm{Hg}$ at one or more oesophageal recording sites, or synchronous contractions at two or more recording sites. ${ }^{8}$ For the unlabelled liquid swallows, mean values for the 10 swallows in each patient were first calculated. The mean values of the individual patients before, during, and after irradiation were then compared. For the labelled swallows, mean values for the group as a whole 
before, during, and after irradiation were derived by pooling the available swallows, because technical problems, such as fragmentation of the bolus in the mouth, rendered the swallow sequence unanalyseable in some instances.

\section{Scintigraphy}

Solid and liquid swallows were replayed as a composite image and displayed on a screen. Using the cricoid marker, the marker at the midpoint of the sleeve sensor, and the isotope in the gastric fundus to define the proximal and distal limits of the oesophagus, the oesophagus was divided into four regions of interest of equal length, each with a side hole manometric recording site at its midpoint. Pharyngeal and gastric regions of interest were also constructed. Timeactivity curves for each region were then generated. ${ }^{9}$ Total transit time was defined as the time between clearance of the bolus from the pharyngeal segment and clearance from the distal oesophageal segment. Clearance from each segment was deemed to have occurred when the activity of the labelled bolus had dropped to $10 \%$ of its peak value. Bolus transit was classified as 'hold up' if the transit time was more than 15 seconds for liquids and greater than 20 seconds for solids. ${ }^{10}$ For total transit, the mean values for solid and liquid swallows before, during, and after irradiation were derived by pooling all available triplicate swallow data for individual patients. The percentages of hold up of both labelled solid and liquid boluses were also calculated from the pooled available individual swallow measurements.

\section{Statistical analysis}

Symptom and endoscopy scores before, during, and after irradiation were analysed using the non-parametric rank sum test $(\text { Koch })^{11}$ and linear regression analysis. The manometric and scintigraphic data obtained from various phases of the experimental protocol were compared, using analysis of variance for multiple comparisons (ANOVA). As the

TABLE II Results in patients at baseline (before), four to six weeks after starting radiation (during), and six to eight weeks after completion of radiation (after)

\begin{tabular}{|c|c|c|c|}
\hline Parameter & Before & During & After \\
\hline $\begin{array}{l}\text { Symptom score } \\
\text { Endoscopy score }\end{array}$ & $\begin{array}{l}0.0(0-0.5) \\
0.0(0-0)\end{array}$ & $\begin{array}{l}3 \cdot 0^{\star}(2 \cdot 5-4 \cdot 0) \\
0 \cdot 0(0-1 \cdot 5)\end{array}$ & $\begin{array}{l}0.0(0-0.5) \\
0.0(0-0)\end{array}$ \\
\hline \multicolumn{4}{|l|}{$\begin{array}{l}\text { Oesophageal scintigraphy } \\
\text { Liquid: }\end{array}$} \\
\hline $\begin{array}{l}\text { Transit time (s) } \\
\text { Hold up (\% tests) }\end{array}$ & $\begin{array}{l}11 \cdot 0(1 \cdot 6) \\
23\end{array}$ & $\begin{array}{l}10 \cdot 3(1 \cdot 4) \\
13\end{array}$ & $\begin{array}{l}13 \cdot 1(2 \cdot 8) \\
21\end{array}$ \\
\hline Solid: & & & \\
\hline $\begin{array}{l}\text { Transit time (s) } \\
\text { Hold up (\% tests) }\end{array}$ & $\begin{array}{l}47 \cdot 4(11 \cdot 4) \\
63\end{array}$ & $\begin{array}{l}51 \cdot 3(10 \cdot 2) \\
78\end{array}$ & $\begin{array}{l}44 \cdot 6(7 \cdot 8) \\
75\end{array}$ \\
\hline \multicolumn{4}{|l|}{$\begin{array}{l}\text { Oesophageal manometry } \\
\text { Unlabelled: }\end{array}$} \\
\hline $\begin{array}{l}\text { Total transit }(\mathrm{s}) \\
\text { Contraction amplitude }(\mathrm{mm} \mathrm{Hg}) \\
\text { Peristaltic failures }(\% \text { tests) }\end{array}$ & $\begin{array}{l}6 \cdot 3(0 \cdot 4) \\
62 \cdot 4(14 \cdot 0) \\
48 \cdot 0\end{array}$ & $\begin{array}{l}7 \cdot 0(0 \cdot 4) \\
65 \cdot 6(13 \cdot 7) \\
49 \cdot 0\end{array}$ & $\begin{array}{l}6 \cdot 4(0 \cdot 3) \\
72 \cdot 2(17 \cdot 5) \\
41 \cdot 0\end{array}$ \\
\hline $\begin{array}{l}\text { Labelled liquid } \\
\text { Total transit (s) } ¥ \\
\text { Contraction amplitude }(\mathrm{mm} \mathrm{Hg}) \ddagger \\
\text { Peristaltic failures (\% tests) }\end{array}$ & $\begin{array}{l}6 \cdot 5(0 \cdot 6) \\
51 \cdot 5(5 \cdot 1) \\
50\end{array}$ & $\begin{array}{l}6 \cdot 1(0 \cdot 5) \\
63 \cdot 6(9 \cdot 2) \\
66 \cdot 67\end{array}$ & $\begin{array}{l}6 \cdot 7(0 \cdot 4) \\
69 \cdot 2(8 \cdot 2) \\
52 \cdot 17\end{array}$ \\
\hline $\begin{array}{l}\text { Labelled solid: } \\
\text { Total transit (s) } \ddagger \\
\text { Contraction amplitude (mm } \mathrm{Hg}) \\
\text { Peristaltic failures }(\% \text { tests) }\end{array}$ & $\begin{array}{l}6 \cdot 1(0 \cdot 5) \\
47 \cdot 4(7 \cdot 9) \\
81 \cdot 8\end{array}$ & $\begin{array}{l}7 \cdot 0(0 \cdot 7) \\
49 \cdot 7(5 \cdot 1) \\
69 \cdot 6\end{array}$ & $\begin{array}{l}9 \cdot 0(1 \cdot 0)^{\star \star} \\
64 \cdot 8(12 \cdot 2) \\
61 \cdot 9\end{array}$ \\
\hline
\end{tabular}

${ }^{\star} \mathrm{p}<0.001,{ }^{\star \star} \mathrm{p}<0.01$, ANOVA; †median (interquartile range); $\ddagger$ mean (SEM). distributions of both symptom and endoscopy scores were skewed, these parameters are shown as median values and interquartile ranges. Manometric and scintigraphic data are shown as mean (SEM). A p value of $<0.05$ was considered significant in all analyses.

\section{Results}

\section{SYMPTOMS}

Before irradiation, all but two patients (patients 1 and 7 ), both of whom had heartburn with/without regurgitation, were free of symptoms. In contrast, all but one patient (patient 5) experienced odynophagia or dysphagia, or both, during mediastinal irradiation (Table I). The two patients (patients 1 and 7) who had pre-existing reflux reported a worsening of their symptoms. There was no significant weight loss in the group as a whole. One patient, however (patient 2), with locally advanced lung cancer, lost $6 \mathrm{~kg}$ during irradiation. Except for the patients with preexisting reflux symptoms, all oesophageal symptoms had resolved six to eight weeks after completion of irradiation.

\section{ENDOSCOPY}

Before irradiation, endoscopy was normal in all but one patient (patient 7) who had two streaks of erythema approximately $1 \mathrm{~cm}$ in length just proximal to the oesophago-gastric junction, consistent with pre-existing reflux oesophagitis.

During radiation therapy, endoscopic abnormalities were found in three patients (patients 1, 3, and 8). In patients 1 and 8, neither of whom had mucosal lesions before irradiation, the changes consisted of patchy mucosal ulceration in the proximal oesophagus. Histological examination of biopsy specimens of these mucosal lesions showed changes consistent with radiation effect. Patient 3 was noted to have candidiasis in the distal oesophagus. Interestingly, the mucosal changes noted before irradiation at the oesophago-gastric junction of patient 7 were no longer visible.

The endoscopic abnormalities noted in all three patients during mediastinal irradiation resolved completely six to eight weeks after its completion. There was no correlation between the severity of oesophageal symptoms and endoscopic lesions.

\section{SCINTIGRAPHY}

\section{Liquid bolus}

Before irradiation, the mean transit time was within normal limits (Table II) although 23\% of the swallows were classified as having 'held up'. During and after irradiation, neither the percentage of swallows that were held up nor mean transit times changed significantly.

\section{Solid bolus}

In contrast to the liquid swallows, $63 \%$ of the 
solid sequences before irradiation were characterised as held up and resulted in a prolongation of mean transit time for solids (defined as greater than 20 seconds). During and after irradiation, no significant changes in the percentage of hold-up of solid swallows or mean transit times were observed.

\section{MANOMETRY}

Unlabelled swallows

No significant changes in the manometric parameters were observed during or postirradiation compared with those measured before irradiation (Table II).

\section{Liquid bolus}

Before irradiation, the transit sequences with bolus hold up were associated with either peristaltic failure $(33.3 \%)$ or hypotensive contractions $(16 \cdot 7 \%)$, at or above the level of hold up. During and after irradiation, however, none of the manometric parameters changed significantly (Table II).

\section{Labelled solid swallows}

Before irradiation, the major pattern of motility associated with hold up of solids was peristaltic failure, accounting for $58 \cdot 3 \%$ of the sequences; $33.3 \%$ were associated with hypotensive contractions. The remainder of the sequences were associated with normal peristalsis. During irradiation, the manometric measurements did not change significantly. In contrast, after irradiation, peristaltic transit time increased (Table II).

\section{Discussion}

This is the first comprehensive study of the effects of mediastinal irradiation on oesophageal function and also the first to examine critically its effects on oesophageal motility. Previous studies have either focused on symptoms and mucosal changes, ${ }^{34}$ or on symptoms and oesophageal transit. ${ }^{5}$

We have confirmed previous observations that symptoms referable to oesophageal dysfunction are almost inevitable during mediastinal irradiation. ${ }^{1}$ Unlike a previous study, ${ }^{4}$ however, there was generally no associated weight loss in our patients. This is likely to be attributable to differences in the characteristics of the patient group. In our study only those patients who were potentially curable were included, in contrast to the previous study in which most patients were treated with palliative intent and therefore were likely to have metastatic disease. ${ }^{4}$

The finding of macroscopic oesophageal mucosal abnormalities during radiation therapy in only three out of eight patients is consistent with the findings of previous studies. ${ }^{34}$ The mucosal changes were mild, confined to the proximal oesophagus, or associated with candidiasis in the distal oesophagus and did not correlate with the severity of oesophageal symptoms. However, biopsy specimens were not obtained in patients with no visual evidence of mucosal damage.

It has been suggested previously that oesophageal symptoms in patients undergoing mediastinal irradiation may reflect disordered oesophageal motility. ${ }^{4}$ We found no evidence to support this concept, there being no significant change in motility or transit associated with radiation therapy. The absence of changes in oesophageal transit conflict with the only other prospective study of oesophageal motor function during mediastinal irradiation. ${ }^{5}$ The discrepant findings can be attributed to differences in the patient selection criteria and methodology between the studies. In the previous study, ${ }^{5}$ patients with structural lesions such as strictures causing mechanical obstruction were not excluded and these abnormalities could have contributed to the observed prolongation of oesophageal transit. It is also possible that the assessment of scintigraphic oesophageal transit in the previous study was influenced by rapid double swallows, which are known to induce abnormal peristaltic responses, ${ }^{12}$ and the inclusion of sequences associated with a fragmented bolus.

The absence of significant changes in oesophageal transit and motility despite the development of oesophageal symptoms in virtually all patients has a number of possible explanations. Firstly, the inclusion in our study of three patients with breast carcinoma who received radiation doses to the oesophagus that were approximately a third of that of the other patients, may theoretically have contributed to our negative findings. However, this seems unlikely since despite receiving lower radiation doses to the oesophagus, two of the three patients had oesophageal symptoms during mediastinal irradiation.

Secondly, it is possible that mediastinal irradiation caused subtle changes in oesophageal motility that were not detected, either because of the relatively small number of patients studied or inadequate sensitivity of the measurements used. Although we studied only eight patients, the data analysis for each phase of the protocol was based on a total of 16 individual patient swallows. It is unlikely therefore that a type II statistical error could have occurred under these circumstances. Although the overall sensitivity of concurrent oesophageal radionuclide scintigraphy and manometry in detecting changes in oesophageal motor function has not been formally assessed by longitudinal studies, the overall sensitivities of radionuclide transit and manometry individually in detecting oesophageal dysmotility have been reported as $75 \%$ and $83 \%$ respectively, ${ }^{13}$ and it is acknowledged that the diagnostic yield for concurrent studies is higher. ${ }^{14}$

Thirdly, small changes in oesophageal function may have been masked by underlying abnormalities in oesophageal function. The relatively high percentage of hold ups of solid and peristaltic failures of both liquid and solid swallows observed in our patients before irradiation is possibly a function of their advanced age, since data in younger subjects from our laboratory 
indicate that the prevalence of these abnormalities is much lower. ${ }^{15}$ Although a younger group of patients may have shown changes in oesophageal motor function during radiation therapy, we do not believe that these data would be representative of the typical population of patients currently subjected to mediastinal irradiation, given the increasing use of chemotherapy instead of radiation for Hodgkin's lymphoma. The significance of our observation that the manometric transit of solid slowed down after irradiation is uncertain since it occurred when oesophageal symptoms had resolved.

The most likely explanation for the development of symptoms in the absence of changes in oesophageal transit and motility is that oesophageal symptoms are the result of exaggerated mucosal sensitivity consequent upon mediastinal irradiation. This increased perception of stimuli in the absence of motility changes has been demonstrated in other parts of the gastrointestinal tract. ${ }^{1617}$ Increased mucosal sensitivity as a result of mediastinal irradiation could lead to the perception of previously asymptomatic bolus hold up. This hypothesis, however, awaits specific investigation.

We wish to thank Mrs S Fitton for her assistance with the manuscript. This study was supported by the Research Review and Special Purposes Fund of the Royal Adelaide Hospital.

1 Roswit B, Malsky SJ, Reid CB. Radiation tolerance of the gastrointestinal tract. In: Vaeth J M, ed. Frontiers of radiation therapy and oncology. Vol 6. Baltimore: University Park Press, 1972: 160-81.

2 Perez CA, Stanley K, Rubin P, Kramer S, Brady L, of various irradiation doses and fractionation schedules in the treatment of inoperable non-oat-cell carcinoma of the lung. Preliminary report by the Radiation Therapy Oncology Group. Cancer 1980; 45: 2722-53.

3 Nicolopoulos N, Mantidis A, Stathopoulos E, et al. Prophylactic administration of indomethacin for irradiation esophagitis. Radiother Oncol 1985; 3: 23-5.

4 Soffer EE, Mitros F, Doornbos F, Friedland J, Launspach J, Summers RW. Morphology and pathology of radiationinduced esophagitis. Double-blind study of Naproxen vs placebo for prevention of radiation injury. Dig Dis Sci placebo for prevent

5 LaManna MM, Parker JA, Wolodzko BS, Zekavat PP Lanna MM, Parker JA, Wolodzko BS, Zekavat PP,
Popky GL. Radionuclide esophageal and intestinal transit scintigraphy in patients undergoing radiation therapy. Radiat Med 1985; 3: 13-6.

6 Dent J. A new technique for continuous sphincter pressure measurement. Gastroenterology 1976; 71: 263-7.

7 Arndorfer RC, Stef J, Dodds WJ, Lineham JH, Hogan WJ. Improved perfusion system for intraluminal oesophageal manometry. Gastroenterology 1977; 73: 23-7.

8 Schoeman MN, Holloway RH. Stimulation and characteristics of secondary oesophageal peristalsis in normal subjects. Gut 1994; 35: 152-8.

9 Blackwell JN, Hannan WJ, Adam RD, Heading RC. Radionuclide transit studies in the detection of oesophageal dysmotility. Gut 1983;24: 421-6.

10 Holloway RH, Lange RC, Plankey MW, McCallum RW. Detection of esophageal motor disorders by radionuclide Detection of esophageal motor disorders by rad
transit studies. Dig Dis Sci 1989; 34: 905-12.

11 Koch GG. Some aspects of the statistical analysis of 'split plot' experiments in completely randomised layouts. $\mathfrak{F} \mathrm{Am}$ Stat Assoc 1969; 64: 485-505.

12 Vanek AW, Diamant NE. Responses of the human oesophagus to paired swallows. Gastroenterology 1987; 92: 643-50.

13 DeCaestecker JS, Blackwell JN, Adam RD, Hannan WJ, Brown J, Heading RC. Clinical value of radionuclide oesophageal transit measurement. Gut 1986; 27: 659-66.

14 Blackwell JN. Oesophageal scintigraphy. In: Read NW, ed. Gastrointestinal motility: which test? Petersfield: Wrightson Gastrointestinal motility: which test? Peter

15 Tippett MD, Holloway RH, Horowitz M, Maddox A, Russo A, Moten J. Esophageal motor function responsible for abnormal esophageal transit in insulin-dependent for abnormal esophageal transit in insulin-depend

16 Mearin F, Cucala M, Azpiroz F, Malagelada J-R. The origin of symptoms on the brain-gut axis in functional dyspepsia. Gastroenterology 1991; 101: 999-1006.

17 Accarino AM, Azpiroz F, Malagelada. Symptomatic response to stimulation of sensory pathways in the jejunum. Am F Physiol 1992; 263: G673-7. 